\title{
DEL ACCESO COMUNAL A LA TIERRA A LA CERTIFICACIÓN PARCELARIA: CAMBIOS EN LA GOBERNANZA AGRARIA
}

\section{From Communal Access to Land, to Land Certification: Changes in Agrarian Governance}

\author{
Emilia Velázquez-Hernández*
}

DOI: http://dx.doi.org/10.29043/liminar.v17i2.675

\begin{abstract}
Resumen: En este texto se reflexiona sobre los complejos procesos sociopolíticos ligados a las transformaciones en los derechos de propiedad agraria promovidos por el Estado mexicano. Para ello se revisa la historia agraria de los pueblos popoluca y nahua asentados en los municipios de Soteapan y Mecayapan, Veracruz. Se analiza el desplazamiento de una modalidad de acceso comunal a la tierra basada en una ciudadanía local, a una forma de tenencia ejidal que supuso la creación de una ciudadanía agraria. Se concluye que la certificación parcelaria promovida por la Ley Agraria de 1992 es la culminación de un proyecto estatal iniciado en el siglo XIX en pro de la propiedad privada e individual.
\end{abstract}

Palabras clave: derechos de propiedad, reparto agrario, certificación agraria, ciudadanía local, ciudadanía agraria.

Abstract: This text reflects on the complex sociopolitical processes linked to the transformations in agrarian property rights promoted by the state. To this end, we review the agrarian history of the Popoluca and Nahua peoples settled in the municipalities of Soteapan and Mecayapan, Veracruz. The shift from a type of communal access to land based on local citizenship is analyzed, as well as a form of ejido possession that would supposedly create an agrarian citizenship. We conclude that the certification of land holdings promoted by the Agrarian Law of 1992 is the culmination of a state project initiated in the 19th century that sought to favor private and individual property.

Keywords: property rights, agricultural land distribution, agrarian certification, local citizenship, agrarian citizenship.

\footnotetext{
* Emilia Velázquez Hernández. Doctora en Ciencias Sociales por El Colegio de Michoacán, México. Profesora-investigadora en el Centro de Investigación y Estudios Superiores en Antropología Social (CIESAS), Unidad Golfo, México. Temas de especialización: antropología política, historia regional. Correo electrónico: emivel@ciesas.edu.mx. ORCID: http://orcid.org/0000-0001-6372-7459.
}

Enviado a dictamen: 20 de septiembre de 2018. Aprobación: 1 de marzo de 2019. Revisiones: 1. 
E reparto agrario posrevolucionario, que con diversas intensidades y orientaciones se llevó cabo en México a lo largo de varias décadas (1917-1991), ${ }^{1}$ y los cambios al artículo 27 constitucional (1992) que dieron lugar a una nueva Ley Agraria y un programa de certificación parcelaria (PROCEDE), ${ }^{2}$ han sido dos eventos nacionales en torno a los cuales se ha transformado profundamente la gobernanza agraria en miles de localidades del país. Las normatividades jurídicas derivadas de uno y otro han sido las bases formales de las modalidades legalmente permitidas -o prohibidas - para acceder y hacer uso de la tierra.

Ahora bien, en torno al proceso de reparto agrario validado por la Constitución de 1917 en su artículo 27, y de la nueva Ley Agraria de 1992 que surgió de los cambios que en dicho año se hicieron al artículo mencionado, se desarrollaron complejos procesos de reformulación de derechos de propiedad en los que se fueron definiendo y redefiniendo quiénes y cómo podían tener acceso a la tierra, quiénes quedaban legalmente excluidos, y qué mecanismos e instancias podían utilizarse para garantizar los derechos de propiedad.

Esta reformulación de derechos de propiedad ha sido un elemento central de la formación del Estado - posrevolucionario y neoliberal一, pues, como afirma Azuela (2010:1916), "el poder estatal se basa, entre otras cosas, en un conjunto de relaciones de propiedad". El mismo autor señala que los cambios que ocurren en las relaciones de propiedad involucran necesariamente transformaciones en "el alcance e intensidad del poder estatal” (Azuela, 2010:1941). De igual manera, Sikor y Lund (2009) argumentan que las luchas y reclamos en torno a la propiedad son parte de los procesos de formación cotidiana del Estado.

Por otro lado, la reformulación de derechos de propiedad es también parte constitutiva del proceso de formación de lo local, es decir, de los espacios de relaciones sociales en los que interactúan cotidianamente los individuos y grupos que hacen uso de tierras y recursos, y que elaboran determinadas formas de ciudadanía local a la luz de la cual se otorgan o deniegan derechos de propiedad o acceso (Lund, 2011). A partir de estos planteamientos teóricos, mi interés en este texto es reflexionar en torno a la manera en que los derechos de propiedad anclados en una ciudadanía agraria avanzaron en detrimento de los derechos de acceso basados en una ciudadanía local. ${ }^{3}$

La ciudadanía agraria a la que me refiero es entendida como el conjunto de derechos y obligaciones con respecto a la tierra otorgada mediante el reparto agrario; por lo tanto, ha sido definida con base en la Ley Agraria federal. Lo que me interesa explorar aquí son las maneras en que dicha ciudadanía agraria se sobrepone -y en ocasiones se contrapone- a una ciudadanía local elaborada a partir de prácticas y arreglos diversos a los que se ha arribado en distintas temporalidades, y en los que han quedado integradas disposiciones estatales de otras épocas.

La tesis que sostengo es que en la elaboración de derechos de propiedad y acceso juegan un papel relevante tanto el poder estatal —expresado en leyes, reglamentos y políticas públicas - como las prácticas locales de exclusión e inclusión históricamente construidas, a partir de las cuales se interpretan y resignifican las disposiciones estatales. Para desarrollar esta tesis, parto de una etnografía histórica que da cuenta de la transición del uso comunal y mancomunado de las tierras por parte de los pueblos popolucas y nahuas que habitan en los municipios de Soteapan y Mecayapan, pasando por el reparto agrario y concluyendo con la certificación parcelaria.

Estos municipios se ubican al sur del estado de Veracruz (México), en la Sierra de Santa Marta, que es una de las dos elevaciones montañosas que se encuentran en la planicie del llamado istmo veracruzano. Actualmente, la Sierra de Santa Marta se distingue por ser el principal núcleo de concentración de población que habla alguna lengua indígena en el sur de Veracruz. De acuerdo con el censo de 2010, la población hablante de lenguas indígenas en los municipios de la Sierra oscilaba entre el 65\% y el $85 \%$ de la población mayor de 3 años (INEGI, 2010). Con relación a la propiedad de la tierra, en el conjunto de la Sierra predomina el régimen ejidal: 69 ejidos, frente a dos colonias agrícolas ganaderas (La Perla del Golfo y La Magdalena, al norte y occidente de la Sierra, 
en los municipios de Mecayapan y Soteapan), y una comunidad agraria (Pajapan). La mayoría de los ejidos se localizan en el municipio de Soteapan (24), seguido de Tatahuicapan (21), Mecayapan (14) y Pajapan (10). ${ }^{4}$

El artículo está organizado de la siguiente manera: en el primer apartado expongo los antecedentes de las tierras comunales de Soteapan-Mecayapan. En la segunda sección me refiero a la transición entre una forma de acceso comunal a la tierra, con escasa o nula intervención estatal, y a una forma de propiedad de la tierra determinada por el Estado a través del reparto agrario. Muestro que, aún después de la reforma agraria, el acceso a tierras y recursos amparado en una ciudadanía local fue lo que predominó. En la tercera parte expongo cómo el parcelamiento de tierras ejidales en la década de 1970 fue determinante para crear una ciudadanía agraria que se sobrepuso a la anterior ciudadanía local basada en la autoctonía. Y en el cuarto apartado narro cómo esta ciudadanía agraria pierde sus antiguas restricciones en el contexto de un mercado de derechos parcelarios inaugurado con la ley de 1992. Las fuentes de información en las que sustento el análisis sobre la relación entre propiedad de la tierra, ciudadanía y formación del Estado son básicamente dos: un trabajo de campo realizado por la autora en diferentes momentos entre 1997 y 2017 en varias localidades de los municipios de Soteapan y Mecayapan, y la revisión de expedientes del fondo Gobernación y Justicia, serie Tierras, del Archivo General del Estado de Veracruz.

\section{Antecedentes de las tierras comunales de Soteapan}

Legalmente, las tierras comunales de Soteapan tuvieron su origen en la compra de dos mercedes de tierras fechadas en 1584 y 1634, mediante las cuales los popolucas de Soteapan adquirieron 14200 hectáreas. ${ }^{5}$ Sin embargo, para los popolucas que habitaban en Soteapan a finales del siglo XIX, esta superficie era sólo una parte de sus tierras comunales, probablemente la que utilizaban para sus labores agrícolas, en tanto que el conjunto de las tierras comunales que reclamaban como propias se extendía por casi toda la Sierra. Para autoridades y pobladores del municipio de Soteapan, sus tierras comunales incluían prácticamente toda la superficie de este municipio y del de Mecayapan, la mayor parte de las cuales estaban cubiertas con selva tropical.

Mientras tanto, las entonces tierras de labor de las tierras comunales de Soteapan eran utilizadas por los vecinos de cuatro pueblos popolucas (Amamaloya, Ocozotepec, Ocotal y Soteapan), tres poblaciones nahuas (Mecayapan, Tatahuicapan y Texistepec) ${ }^{6}$ y un conjunto de rancherías habitadas por popolucas (Cuilonia, Santa Rita, Palmar, Loma Larga, Horno de Cal, Sabaneta, Cerro Grande, Aguacate, Sogotegollo, Tulín y Chichipan). El total de comuneros que en 1898 ocupaban dichas tierras ascendía a 1133 jefes de familia.?

Como he explicado en otras publicaciones (Velázquez, 2006 y 2009), los pobladores de Soteapan no lograron deslindar ni dividir las tierras comunales que reclamaban como propias (98 510 hectáreas), ${ }^{8}$ ya que cuando tardíamente (1894) iniciaron este proceso la mayor parte de dichas tierras habían sido declaradas terrenos baldíos y adjudicadas al Lic. Manuel Romero Rubio. ${ }^{9}$ En noviembre de 1902, el gobernador del estado ordenó que el jefe político del cantón de Acayucan, el síndico del ayuntamiento de Soteapan y el representante de este pueblo se trasladaran a la capital del estado llevando consigo sus títulos y comprobantes que acreditaran la propiedad de sus tierras comunales; esto con la finalidad de cotejar tales documentos con los presentados por los abogados de las herederas de la testamentaría de Romero Rubio. Después de realizado el cotejo, se concluyó que el pueblo de Soteapan sólo era propietario de once sitios de ganado mayor y cuatro caballerías de tierra -19 582 hectáreas, 89 áreas y 21 metros-, las cuales debían ubicarse en las inmediaciones del pueblo, tomándose como centro de dicha extensión la iglesia del mismo. ${ }^{10}$

Pese a la inconformidad expresada de diversas maneras - pacíficas y violentas - por los campesinos popolucas de la comunidad de Soteapan, la mayor parte de lo que ellos consideraban sus tierras comunales pasó a ser propiedad de las herederas Romero Rubio. Ese mismo año, estas mujeres alquilaron las antiguas tierras de Soteapan al empresario inglés Wheetman 
Pearson. ${ }^{.1}$ Para entonces, este empresario contratista ${ }^{12}$ se había volcado al negocio de la explotación y refinación de petróleo, a la vez que había adquirido grandes extensiones de tierra tanto en la parte veracruzana como oaxaqueña del Istmo de Tehuantepec (Azaola, 1982; Prévôt-Schapira, 1994). En este contexto, en 1905 Pearson compró los antiguos terrenos comunales de Soteapan, ahora denominados segunda zona B de Romero Rubio, y que abarcaban 39233 hectáreas en el municipio de Mecayapan y 39325 hectáreas en el de Soteapan. ${ }^{13}$

Si bien Soteapan mantuvo la propiedad de su fundo legal y una superficie para actividades agrícolas, Mecayapan quedó carente incluso de los terrenos en los que se ubicaba su cabecera municipal, de tal forma que debieron comprar a la Sucesión Romero Rubio una superficie de tres sitios de ganado mayor, pagando por ello 9000 pesos. En el contrato de compraventa celebrado entre el ayuntamiento de Mecayapan y la Sucesión Romero Rubio, ésta se reservaba "los derechos al subsuelo y la propiedad de todas las substancias que en él se encuentren, con especialidad minerales, carburos e hidrocarburos de hidrógeno y sus derivados y en lo general la propiedad de todas aquellas substancias que existen en el subsuelo y que por ley le pertenecen al propietario del terreno". Además, la mencionada Sucesión conservaba "el derecho de establecer en cualquier punto del terreno máquinas, oficinas, ferrocarriles, acueductos, telégrafos, teléfono y en lo general podrá llevar a cabo todas aquellas instalaciones y efectuar todas las obras que se requieran y sean necesarias, para la exploración y explotación del subsuelo $\left[\ldots . . .{ }^{14}\right.$

Sin embargo, por alguna razón, probablemente relacionada con la escasa productividad petrolera del sur de Veracruz, en comparación con la riqueza de la denominada faja de oro en el norte de este mismo estado, y donde Pearson también tenía inversiones, ${ }^{15}$ las tierras de los municipios de Soteapan y Mecayapan permanecieron intocadas por la Compañía Mexicana de Petróleo El Águila, que Pearson fundó en 1908. Cinco años después, en 1913, las tierras que Pearson había adquirido en Soteapan y Mecayapan pasaron a formar parte de la Compañía Mexicana de Bienes Inmuebles, en la que Pearson figuraba como principal accionista. ${ }^{16}$ Esta compañía mantuvo la propiedad de dichas tierras hasta 1948, gracias a un amparo mediante el cual intentó salvarlas de la expropiación de los bienes de las compañías petroleras extranjeras decretadas por el presidente de la República Lázaro Cárdenas en 1938.

\section{El reparto agrario $v$ s. la fuerza de una ciudadanía local}

No obstante que las tierras eran propiedad de la Compañía Mexicana de Bienes Inmuebles, campesinos nahuas y popolucas las continuaron utilizando para sembrar maíz, frijol, caña de azúcar y café, además de para pescar, cazar y recolectar productos diversos, así como para fundar nuevos poblados. El paso de estas tierras al patrimonio de Petróleos Mexicanos en 1948, y cuya explotación fue cedida a la Secretaría de Agricultura y Ganadería en 1951, no impidió que siguieran bajo control de popolucas y nahuas mediante una modalidad de acceso manconumado y comunal a las tierras.

El uso mancomunado significaba que nahuas y popolucas podían abrir tierras al cultivo en cualquier parte del territorio que se había creado en torno a las tierras comunales reclamadas como propias por el pueblo popoluca, en tanto que el acceso comunal a las tierras se expresaba en un usufructo individual de aquellos terrenos en los que el usuario hubiera invertido trabajo para hacerlas productivas. Este usufructo podía ser vitalicio y hereditario, pero también cabía la posibilidad de que el terreno en cuestión se abandonara para ocupar otro que resultara más atractivo por su potencial productivo o por su cercanía al lugar de residencia. En este caso, la tierra era ocupada por otro campesino, pero el primero mantenía la propiedad sobre la producción de los árboles — naranja, mango, papaya, plátanos- que ahí hubiera sembrado, de tal forma que en cualquier momento podía ingresar a su antigua parcela para recoger los frutos de sus árboles. De igual manera, cualquier miembro de la comunidad podía internarse en cualquier parcela a recoger la leña que necesitara para sus usos domésticos. 
Es decir, el uso de la tierra y sus recursos, mantenido por popolucas y nahuas al interior de una extensa superficie que legalmente no les pertenecía, conllevaba una compleja articulación entre acceso comunal y apropiación individual, sancionada no por una institución político-legal, sino por una norma local. Pero, ¿quiénes podían acceder a estas tierras que popolucas y nahuas asumían que en el pasado habían pertenecido al pueblo de indios de Soteapan? Cualquier miembro de las comunidades nahua y popoluca de Mecayapan y Soteapan, no así los mestizos y zapotecos que en las décadas de 1930 y 1940 comenzaron a asentarse en la cabecera municipal de Soteapan para dedicarse al comercio, y a quienes las autoridades municipales les asignaron solares en el fundo urbano, ${ }^{17}$ pero de ninguna manera se les dio acceso a parcelas en las áreas de cultivo. Así, el acceso a la tierra en esos años estaba subordinado a una forma de ciudadanía local regida por la autoctonía, según la cual los únicos que tenían derecho para reclamar derechos sobre tierras y recursos eran los antiguos pobladores popolucas y nahuas.

En 1931, un grupo de notables popolucas emprendió el primer trámite para recuperar sus antiguas tierras comunales. Este trámite, realizado a través de la Liga de Comunidades Agrarias con sede en Acayucan, quedó registrado como solicitud de tierras en ejido. Sin embargo, pocos años después, el perito agrario enviado a Soteapan por la comisión local agraria reportó que las autoridades de Soteapan no estaban solicitando tierras para formar un ejido, sino que querían que se les devolvieran sus tierras comunales para seguir usándolas en forma mancomunada con campesinos de varios poblados popolucas y nahuas. En 1936 se abrió un nuevo expediente, pero esta vez solicitando restitución de tierras. Después de casi tres décadas en las que la restitución de tierras fue sistemáticamente negada, ${ }^{18} \mathrm{y}$ ante el acoso de ganaderos mestizos que trataban de obtener tierras bajo la modalidad de colonias agrícolas ganaderas en los municipios de Mecayapan y Soteapan, argumentando que las tierras de estos municipios eran de propiedad nacional, los campesinos de las distintas localidades aceptaron la dotación de un ejido para cada poblado.
En los municipios de Soteapan y Mecayapan el reparto agrario inició en la década de 1950, y tuvo su mayor auge en los años 1960-1963, cuando se otorgaron tierras en ejido o se cumplimentaron las dotaciones provisionales de la década anterior. ${ }^{19}$ Para el caso del ejido Soteapan, la resolución presidencial de 1963 indicaba que se expidieran certificados de derechos agrarios a 174 beneficiarios y a la escuela del lugar. ${ }^{20}$ Esta resolución de dotación ejidal se basaba en un censo levantado en 1933, sin tomar en cuenta que en los treinta años que habían transcurrido desde la solicitud de tierras hasta la dotación ejidal, el número de jefes de familia, y de jóvenes en edad de convertirse en tales, había aumentado considerablemente. Tal situación fue advertida en 1962 por el comité agrario de Soteapan, el cual entregó a las autoridades agrarias una lista de campesinos que residían en la localidad y que trabajaban las tierras de lo que habría de convertirse en el ejido Soteapan, solicitando que se volviera a levantar un censo pues, de acuerdo con su lista, no eran 174 sino 326 las personas que trabajaban en las tierras de Soteapan. ${ }^{21}$ Sin embargo, tal solicitud no fue atendida y la dotación ejidal en Soteapan excluyó legalmente del uso de la tierra a cerca del $50 \%$ de los campesinos en activo.

Esta exclusión al uso de la tierra para quienes no habían quedado registrados en el censo ejidal de 1933 se resolvió mediante una decisión local que, en los hechos, contradecía la determinación estatal de repartir la tierra entre 174 beneficiarios: mantener el acceso comunal a la tierra al interior del ejido. Esto significó que, igual que en el pasado, todo miembro de la comunidad podía hacer uso de las tierras, ahora categorizadas por el Estado como tierras ejidales, haciendo caso omiso de la distinción entre ejidatario y no ejidatario establecida por la Ley Agraria. Esta medida se ajustaba a una concepción local de la tierra como un bien para el beneficio común, significando esto que el acceso a la tierra estaba legitimado por la pertenencia comunitaria, aunque era el trabajo individual y familiar el que aseguraba un usufructo que podía ser indefinido. El acceso comunal a las tierras ejidales se tradujo en una nueva categoría agraria local, la de "ejido comunal", el cual cobijaba a ejidatarios y 
"comuneros", es decir, campesinos de la comunidad que no habían sido dotados con tierras ejidales. De esta manera, el acceso comunal a la tierra se evidenciaba notablemente más incluyente que el reparto agrario.

\section{El parcelamiento de ejidos comunales: el paso de una ciudadanía local a una ciudadanía agraria}

El acceso comunal a la tierra sufrió un fuerte revés en la década de 1970, no por la intervención de alguna autoridad agraria, sino por el avance de la ganadería extensiva, una actividad económica promovida por algunas dependencias gubernamentales, pero también autofinanciada mediante la inversión de ganancias obtenidas de la comercialización del maíz y frijol que se sembraba en las tierras de los ejidos.

Hasta entonces, el acceso comunal a la tierra había sido compatible con la siembra de maíz con espeque —que aún se usa en la sierra-, ya que difícilmente alguien podía sembrar más de dos o tres hectáreas de maíz en terrenos donde el uso de tractores, e incluso de yuntas, era prácticamente imposible. Sin embargo, la adopción de la ganadería extensiva, con su necesidad de cercar extensiones mayores de tierra para la engorda de ganado bovino, hizo aparecer los llamados "encierros". En éstos, un grupo de familias emparentadas por lazos consanguíneos o simbólicos se reunía para invertir en la compra de alambre de púas y cercar entre cien y trescientas hectáreas de terreno, sustrayendo así estas tierras al acceso comunal para la agricultura, y originando múltiples y muchas veces violentas confrontaciones al interior de las comunidades. ${ }^{22}$

Tal situación ocasionó que, a mediados de la década de 1970, al interior de algunos ejidos nahuas (Tatahuicapan, Ixhuapan) y popolucas (Cuilonia, Amamaloya) empezara a gestarse la exigencia de asumir lo establecido en las resoluciones presidenciales de dotación de ejidos, las cuales estipulaban que las tierras ejidales debían ser usufructuadas únicamente por los ejidatarios, y que cada uno de éstos sólo tenía derecho a ocupar la superficie con la cual había sido dotado, y que en la Sierra fue en general de veinte hectáreas por ejidatario. Si bien los ejidatarios inconformes con los "encierros" acudieron a la autoridad agraria para tramitar el parcelamiento de sus ejidos, éste generalmente se ejecutó bajo la modalidad de "parcelamiento económico". Es decir, los ejidatarios contrataron de manera particular a ingenieros topógrafos para que midieran y dividieran las tierras ejidales, asignando una parcela a cada ejidatario. Este proceso de parcelamiento no estuvo exento de conflictos e inequidades pues, según los recuerdos de quienes participaron en el mismo, fue frecuente que los ejidatarios allegados a los comisarios ejidales, o a los ganaderos, se quedaran con las parcelas mejor valoradas - por ubicación, calidad de la tierra o disposición de ojos de agua-.

Dos cuestiones me interesa destacar de este proceso de parcelamiento. En primer lugar, recurrir a éste significó el desplazamiento de una ciudadanía local anclada en la autoctonía, por una ciudadanía agraria basada en la pertenencia al ejido y ya no a la comunidad indígena. A partir de entonces, el derecho a reclamar derechos sobre las tierras y sus recursos se circunscribió a los integrantes del ejido. En segundo lugar, el parcelamiento significó pasar del acceso a la propiedad de la tierra, y con ello al predominio de una determinada institución político-legal sobre las normas locales, participando así del proceso de formación de un Estado que todavía tenía - al menos en el discurso - la reforma agraria y la propiedad social de la tierra como sus ejes fundantes.

\section{La certificación parcelaria: una ciudadanía agraria abierta al mercado}

Hacia finales de la década de 1970, el acceso comunal a la tierra desapareció en todos los ejidos en los que la ganadería se estaba convirtiendo en la principal actividad productiva, pero se mantuvo en los ejidos dedicados principalmente al cultivo de maíz y, sobre todo, de café. Se constituyó así un reducto de ejidos comunales localizados la gran mayoría de ellos en el municipio de Soteapan. Las tierras de estos ejidos -Soteapan, San Fernando, Ocotal Grande, Ocotal Chico, Ocozotepec, Sierra de Santa Martha, Buenavista, Colonia Benito Juárez, Tulín, Plan Agrario— siguieron 
siendo usadas por ejidatarios y comuneros hasta mediados de la década de 1990, cuando comenzó a parcelarse la tierra en casi todos ellos. ${ }^{23}$

A diferencia de lo ocurrido en la década de 1970, cuando la decisión de parcelar provino básicamente del interior de los ejidos, en tanto que la autoridad agraria sólo fue requerida para legitimar el parcelamiento impulsado y ejecutado desde los ejidos, esta vez el Estado tuvo un papel relevante en la promoción y realización del parcelamiento. En esa ocasión hubo una nueva disposición legal y un Programa de Certificación de Derechos Ejidales y Titulación de Solares (PROCEDE) a disposición de los ejidatarios para hacer valer sus derechos de propiedad, y para vender dichos derechos.

En el puñado de ejidos comunales que quedaban en el municipio de Soteapan, el parcelamiento se volvió una opción deseable para la mayoría de los ejidatarios cuando a éstos se les informó que había una nueva Ley Agraria que posibilitaba la obtención de un título parcelario que podrían vender si así lo desearan o necesitaran. Entre 1993 y 1994, en estos ejidos se debatió con intensidad la opción de parcelar y se vivieron importantes confrontaciones intracomunitarias, particularmente entre ejidatarios y comuneros, quienes trataron de permanecer en las tierras del ejido hasta el último momento. Algunos comuneros se organizaron para intentar resistir, mediante la presión política y la vía jurídica, a ser desalojados de las tierras que habían ocupado por años; otros más hicieron tratos con el ejidatario en cuya parcela tenían su milpa, logrando a veces que el primero les dejara seguir sembrando y cobrando el apoyo de PROCAMPO ${ }^{24}$ hasta que hubiera concluido el PROCEDE. También hubo conflictos y negociaciones entre ejidatarios que pretendían adquirir el control de toda su parcela, e hijos que reclamaban que sus padres les cedieran legalmente pequeñas parcelas, con lo cual quedarían registrados como posesionarios y posiblemente como nuevos ejidatarios. Otros conflictos ocurrieron entre hermanos, y fueron ocasionados por el descontento de aquellos que no fueron favorecidos por el padre ejidatario, ya fuera otorgándoles una pequeña extensión de la parcela, o cediendo la totalidad de ésta a alguno —o alguna- de los hijos.
Las soluciones fueron variadas entre los diferentes ejidatarios, unas menos excluyentes que otras, pues hubo ejidatarios que repartieron su parcela entre sus hijos, pero solamente entre los varones; otros no quisieron repartir su parcela, pero permitieron a sus hijos trabajar en ella; unos más incluyeron a las hijas en el reparto de pequeñas extensiones de sus parcelas; y algunos más dieron su parcela a una hija o nieta que los atendía y cuidaba, pese al enojo de los hombres de la familia. Sin embargo, en cuanto a la decisión colectiva tomada en los ejidos, lo que predominó fue la exclusión de los comuneros y avecindados de las tierras ejidales, paliada en mucho por las decisiones individuales de ceder pequeñas superficies a hijos o nietos, o de vender alguna extensión de las mismas, ya fuera a otro ejidatario, a un comunero o a un avecindado. Una u otra de estas dos opciones ocurrió durante el tiempo transcurrido entre el momento en que la asamblea de ejidatarios decidió aceptar el PROCEDE y aquel en el que personal del INEGI acudió a medir las parcelas.

Es por ello que en prácticamente todos los ejidos el número de ejidatarios registrados ante el Registro Agrario Nacional —en el Padrón e Historial de Núcleos Agrarios, PHINA - superó con mucho al número de ejidatarios originales. En algunos casos, el total de ejidatarios, una vez concluido el PROCEDE, tuvo un crecimiento moderado respecto a los sujetos de derecho originales: así, en Kilómetro Diez los ejidatarios pasaron de 22 a 30, en El Tulín de 81 a 92, y en Popsojnas y Reforma Agraria de 25 a 28. Sin embargo, en la mayoría del resto de los antiguos ejidos comunales, el número de ejidatarios creció al doble o más de las dotaciones originales: por ejemplo, en Ocozotepec se pasó de 192 ejidatarios a 364, en Gral. Hilario C. Salas de 47 a 105, en Soteapan de 174 a 363, y en Tierra y Libertad de 60 a 109. En otros pocos ejidos el número de ejidatarios casi se triplicó o incluso sobrepasó tal cantidad: Morelos pasó de 60 a 109 ejidatarios, en tanto que en Ocotal Chico se pasó de 55 a 188 ejidatarios. ${ }^{25}$

Sólo en un ejido, San Fernando, se optó por repartir el conjunto de las tierras ejidales entre todos aquellos que estaban haciendo uso de ellas al momento del parcelamiento, fueran ejidatarios o 
no, por lo que al concluir el PROCEDE el número de ejidatarios que quedó registrado ante el Registro Agrario Nacional superó en más de seis veces al número de sujetos de derecho originales: 532 ejidatarios y 13 posesionarios-, frente a los 87 ejidatarios beneficiados por la dotación de $1963 .{ }^{26}$

Así, en estos ejidos que hasta principios de la década de 1990 funcionaron amparados en una categoría local — ejido comunal- que no restringía el uso de las tierras a los ejidatarios, los rescoldos del antiguo acceso comunal a la tierra permitieron que muchos comuneros, principalmente hijos de ejidatarios, se convirtieran en ejidatarios con el PROCEDE. Si bien en los municipios vecinos a Soteapan, con el cobijo de este programa gubernamental también ocurrió el registro de nuevos ejidatarios, en ningún caso el número de éstos aumentó en las proporciones observadas en Soteapan. ${ }^{27}$

Así, en estos ejidos ahora parcelados bajo el PROCEDE, el derecho a reclamar derechos sobre la tierra quedó circunscrito a los ejidatarios, igual que en la década de 1970 había sucedido con el parcelamiento en los ejidos ganaderos. Sólo que esta vez el derecho a la tierra ya no quedó limitado al derecho a trabajarla, sino que se adquirió el derecho a venderla. El artículo 80 de la Nueva Legislación Agraria establece que: "Los ejidatarios podrán enajenar sus derechos parcelarios a otros ejidatarios o avecindados del mismo núcleo de población", y añade que:

Para la validez de la enajenación a que se refiere este artículo, bastará la conformidad por escrito de las partes ante dos testigos y la notificación que se haga al Registro Agrario Nacional, el que deberá expedir sin demora los nuevos certificados parcelarios. Por su parte el Comisariado Ejidal deberá realizar la inscripción correspondiente en el libro respectivo (Procuraduría Agraria, 1993:68).

Los cambios de 1992 al artículo 27 constitucional no sólo permiten la venta de certificados parcelarios de un ejidatario a otro, o de un ejidatario a un avecindado, sino que también abren la puerta al cambio de propiedad ejidal a propiedad privada, tal como se indica en los artículos 81 y 82: "Cuando la mayor parte de las parcelas de un ejido hayan sido delimitadas y asignadas a los ejidatarios en los términos del artículo 56, la Asamblea [...] podrá resolver que los ejidatarios puedan a su vez adoptar el dominio pleno sobre dichas parcelas". Y una vez ocurrido esto: "los ejidatarios interesados podrán, en el momento que lo estimen pertinente, asumir el dominio pleno sobre sus parcelas, en cuyo caso solicitarán al Registro Agrario Nacional que las tierras de que se trate sean dadas de baja de dicho Registro". Después dichas tierras deberán quedar inscritas en el Registro Público de la Propiedad correspondiente (Procuraduría Agraria, 1993:68).

Al amparo de esta nueva normatividad agraria, en varios ejidos, particularmente los ubicados en las cabeceras municipales y en las zonas ganaderas, se ha desarrollado un mercado de tierras ejidales de diversa magnitud, aunque manteniendo la tenencia ejidal (Flores, 2007). Debido a este mercado de tierras, la ciudadanía local basada en la autoctonía, que fue central en periodos anteriores para tener derecho al uso de tierras, prácticamente desapareció. No obstante que el artículo 80 de la Ley Agraria vigente establece que los ejidatarios sólo podrán enajenar sus derechos parcelarios a otros ejidatarios o avecindados del mismo núcleo de población (Procuraduría Agraria, 1993:68), en la Sierra estos lineamientos no se han cumplido. En el ejido Soteapan, por ejemplo, se han vendido derechos parcelarios a personas que no son ni ejidatarios ni avecindados: "después de que los ejidatarios recibieron sus certificados parcelarios ha habido muchas ventas de parcelas, la mayoría a gente de fuera, principalmente de Tatahuicapan, Minatitlán y Xalapa. Algunos [de estos compradores] usan la parcela para ganadería, otros las compran y no las usan". ${ }^{28}$ En 2016, un ejidatario que en años recientes había sido integrante del comisariado ejidal reconocía la existencia de alrededor de quince ejidatarios foráneos, cuya residencia se localizaba en ciudades como Acayucan, Coatzacoalcos, Minatitlán, Puebla y Xalapa, ${ }^{29}$ algunas de cuyas parcelas estaban sin ocupar. ${ }^{30}$ Esta anomalía en la venta de derechos parcelarios no ha sido cuestionada ni por la Procuraduría Agraria ni por las autoridades ejidales. 
Por otra parte, con la expedición de títulos parcelarios el aprovechamiento individual y privado de tierras y recursos se convirtió en la forma casi única de organización ejidal. En los ejidos de la Sierra es inexistente el concepto de áreas para usos comunes o colectivos; a diferencia de lo que se observa en otras regiones del país, en la Sierra los ejidos fueron dotados de una determinada superficie para las parcelas de los beneficiarios del reparto agrario y un área para el núcleo urbano. Así, cuando los ejidos se parcelaron, toda la superficie se dividió en parcelas individuales, con lo que tanto las parcelas como los recursos que ahí se encontraban se convirtieron en un asunto particular, sin que el resto de los ejidatarios se sienta con derecho alguno a cuestionar las decisiones que cada quien toma con relación a su parcela, aun cuando atenten contra asuntos que atañen a la colectividad.

Al parcelarse las tierras ejidales, los ejidatarios se asumieron como propietarios con derecho absoluto sobre su parcela y lo que en su interior pudiera existir. Fue así como los cafeticultores de varios ejidos perdieron el derecho a usar un beneficio de café construido en 1993 con dinero público, a través del Instituto Nacional Indigenista (INI), en el ejido Soteapan. Lo mismo ocurrió con la cascada mayor, un lugar de esparcimiento para la gente de Soteapan, Minatitlán y Acayucan, pues una vez que se hizo el parcelamiento, el ejidatario a quien le correspondió la parcela en la que se ubica la cascada vendió su certificado parcelario con todo y el derecho a beneficiarse privadamente de la cascada. El nuevo ejidatario, una persona externa al ejido y al poblado, cercó la parcela y empezó a cobrar a la gente que quería ir a bañarse en la poza que se forma en la caída del agua de la cascada. Al poco tiempo, otro ejidatario en cuya parcela se ubica la llamada cascada menor también cerró el paso a la misma y empezó a cobrar por ir a ese lugar a pasear y bañarse.

Algo semejante ocurrió con una laguna artificial que existe en el ejido: si antes del parcelamiento cualquier persona de Soteapan podía entrar a pescar, después de éste la laguna se volvió de uso exclusivo de dos ejidatarios en cuyas parcelas se encuentra este cuerpo de agua. En 2017, un ejidatario más obtuvo un apoyo monetario de la Comisión Nacional para el Desarrollo de los Pueblos Indígenas (CDI) para establecer un centro ecoturístico en su parcela. Ésta se encuentra a orillas del poblado; por ella pasa un tramo del río Huazuntlán y existen unas "resbaladillas" naturales a las que acostumbraban ir los niños del pueblo a jugar. Debido a ello, actualmente hay que pagar por hacer uso de este lugar de esparcimiento. Algo similar ha sucedido con otro centro ecoturístico en un ejido cercano, Amamaloya, en donde CDI ha canalizado importantes recursos financieros para la construcción de un hotel en la parcela de un ejidatario. Algunas personas del lugar se quejan de las prohibiciones establecidas por el propietario de la parcela para que hombres y mujeres laven caballos y ropa en ciertos tramos del río que pasa por el centro ecoturístico, y que es uno de sus atractivos. Más allá de la discusión sobre cuestiones ambientales, lo que interesa señalar son las contradicciones y tensiones entre la apropiación individual y privada de los recursos frente a los usos colectivos de los mismos. Estos últimos estuvieron garantizados mientras se mantuvo el acceso comunal a la tierra al interior de los ejidos (Soteapan), e incluso cuando los ejidos se parcelaron en la década de 1970 (Amamaloya) en el contexto de una Ley Agraria que sólo concedía a los ejidatarios el derecho al usufructo de la parcela. Sin embargo, el otorgamiento de títulos parcelarios en el marco de una ley que permite la venta de dichos títulos ha conducido a una privatización y mercantilización de recursos que, en términos estrictos, son propiedad de la nación, como cascadas y ríos.

\section{Algunas conclusiones}

Entre finales del siglo XIX y las postrimerías del siglo XX, la mayoría de los pueblos indígenas en México debieron enfrentar cambios importantes en sus formas de propiedad de la tierra, viéndose obligados a ajustarse a determinadas disposiciones estatales - división y reparto de tierras comunales, obtención de tierras por dotación ejidal, certificación parcelaria- orientadas a instaurar formas de propiedad agraria acordes con proyectos de nación definidos por las élites políticas 
de cada época. Los procesos de instauración de nuevas formas de propiedad no sólo han sido complejos y diversos, sino que muchas veces han requerido de varias décadas para anclarse localmente, y este anclaje muchas veces ha sido fallido o parcial.

Para el caso de los pueblos indígenas de Soteapan y Mecayapan, la división de tierras comunales ordenada por la ley de 1856 nunca se concretó. ${ }^{31}$ Y no obstante que las tierras dejaron de ser propiedad legal de los popolucas de Soteapan, este pueblo durante casi medio siglo mantuvo de hecho una ocupación y control de la tierra basada en el acceso comunal y mancomunado a la misma. El reparto agrario, con sus nuevas disposiciones jurídicas y políticas, fue aceptado después de transcurridas poco más de cuatro décadas de promulgada la Constitución de 1917 en la que quedó establecida (artículo 27) la obligación del Estado de dotar de tierras ejidales a los campesinos sin tierras. Sin embargo, la adopción de esta normatividad agraria fue parcial, ya que ésta se entretejió con normas locales de acceso a la tierra vinculadas a etapas históricas anteriores, dando lugar a la existencia de "ejidos comunales", modalidad que en varias localidades de Soteapan fue vigente hasta principios de los años 1990.

En este contexto, destaca por contraste la rápida adopción de la certificación agraria en Soteapan, municipio en el que existía el último reducto de "ejidos comunales". En efecto, en la gran mayoría de los ejidos del municipio de Soteapan el PROCEDE concluyó entre 1995 y 1999, y sólo en cuatro de ellos el parcelamiento quedó inscrito en el Registro Agrario Nacional hasta la siguiente década, a escasos trece años de haberse aprobado la nueva Ley Agraria que permite la enajenación de los títulos agrarios que amparan la propiedad de una parcela dada. ${ }^{32}$

¿Por qué en esta ocasión las disposiciones estatales fueron aceptadas con tal celeridad, en comparación con los períodos anteriores? Propongo como posible explicación la conjunción de varios factores: la mayoría de los ejidatarios actuales son hijos y nietos de los ejidatarios originales, por lo que para ellos la lógica local que permeó la decisión de mantener el acceso comunal a las tierras de los ejidos cuando éstos se crearon entre finales de la década de 1950 y principios de la de 1960, había perdido vigencia; de igual forma, la violencia intracomunitaria que durante más de treinta años asoló a Soteapan a causa de la pugna entre quienes apostaban por la restitución de tierras y aquellos que estaban conformes con la dotación de ejidos, era una historia lejana - y a veces casi desconocida — para los nuevos ejidatarios; por otra parte, el deseo de algunos ejidatarios de parcelar las tierras ejidales estaba presente cuando menos desde la década de 1980, sólo que entonces todavía tenían influencia sobre los ejidos varios de los ejidatarios originarios, quienes temían que se repitieran las emboscadas y los asesinatos por la tierra que les había tocado presenciar en décadas anteriores; además, ante la información de que el gobierno federal daba por terminado el reparto agrario, la mayoría de los ejidatarios consideró que era mejor poseer un título que les garantizara la propiedad de sus parcelas.

La aceptación del parcelamiento y certificación parcelaria significó el reconocimiento pleno y el fortalecimiento de la institución política estatal encargada de sancionar una forma de propiedad, en detrimento de una normatividad local basada en el acceso a la tierra. Vista como proceso, la certificación parcelaria puede considerarse la culminación de un proyecto estatal en pro de la propiedad privada e individual iniciado cien años antes. Por otra parte, no debe olvidarse que los regímenes de propiedad no son ajenos a la creación de formas particulares de ciudadanía. En el caso aquí expuesto, se transitó de una ciudadanía local anclada en la autoctonía, a una ciudadanía agraria definida por disposiciones y leyes estatales de la que sólo podían gozar determinadas personas, los ejidatarios. Finalmente, esta ciudadanía agraria sigue estando ligada exclusivamente a quienes poseen un certificado parcelario, pero ahora está disponible en un mercado de tierras que antes de 1992 era casi inexistente en la región.

\section{Notas}

1 De acuerdo con Zorrilla (1998:7), mientras que en 1917 había 8400 hacendados controlando 114 millones de hectáreas, después de 80 años de reparto agrario existían 
3.5 millones de ejidatarios y comuneros, distribuidos en 30000 núcleos agrarios, que tenían en posesión y usufructo 106 millones de hectáreas.

2 PROCEDE: Programa de Certificación de Derechos Ejidales y Titulación de Solares.

${ }^{3}$ Para pensar desde un nuevo ángulo una etnografía histórica de la que he dado cuenta en otro trabajo (Velázquez, 2006), ha sido fundamental la revisión del trabajo de Sikor y Lund (2009), en el que estos autores teorizan sobre la distinción político-legal entre acceso y propiedad, así como la lectura del trabajo de Lund (2011) sobre la relación entre propiedad y ciudadanía.

${ }^{4}$ Datos obtenidos en www.phina.ran.gob.mx/phina2/ sessiones (consultado el 3 de noviembre de 2016).

${ }^{5}$ AGEV, fondo Secretaría de Gobierno, sección Gobernación y Justicia, serie Tierras, caja 434, exp. 8.

${ }^{6}$ En ese entonces, éstos eran los únicos pueblos habitados por nahuas del municipio de Mecayapan. La presencia de estos nahuas ocupando las tierras de Soteapan se debía a que en algún momento del siglo XVI las autoridades popolucas permitieron que un grupo de pobladores nahuas provenientes del antiguo señorío Ahualulco (en el actual Tabasco) se establecieran en sus tierras. Dichos nahuas ahualulcos huían de las incursiones de piratas que asolaban a los pueblos establecidos cerca de lagunas y ríos que desembocaban al mar (García de León, 2004).

7 AGEV, fondo Secretaría de Gobierno, sección Gobernación y Justicia, serie Tierras, caja 434, exp. 8.

8 En 1899, el ingeniero Ismael Loya, contratado por la municipalidad de Soteapan para hacer el deslinde de las tierras comunales, señalaba que los terrenos que estaba midiendo abarcaban aproximadamente dicha superficie (AGEV, Secretaría de Gobierno, sección Gobernación y Justicia, serie Tierras, caja 434, exp. 8).

9 Manuel Romero Rubio, además de haberse convertido en 1881 en suegro del presidente Porfirio Díaz, fue su secretario de Gobernación entre 1884 y 1895, fecha de su muerte, y el personaje más influyente del gabinete del Gral. Díaz durante este período (Garner, 2003:106).

10 AGEV, fondo Secretaría de Gobernación, sección Gobernación y Justicia t. 3o, serie Tierras, caja 439, exp. 17.
${ }^{11}$ Dicho contrato de alquiler se celebró el 25 de julio de 1902 (AGEV, Secretaría de Gobernación, sección Gobernación y Justicia, serie Tierras, caja 442, exp. 31).

${ }^{12}$ Weetman Pearson tuvo numerosos contratos del gobierno de Porfirio Díaz para la construcción de infraestructura orientada a la modernización del país: el gran canal de desagüe del valle de México, el drenaje de Veracruz, el Ferrocarril Nacional de Tehuantepec, las obras portuarias de Veracruz, Coatzacoalcos y Salina Cruz (Garner, 2013:387-388).

13 Informe presentado en 1928 por el apoderado legal de la Compañía Mexicana de Bienes Inmuebles S.A., al presidente de la Comisión Local Agraria (ACAM, expediente 1432, dotación de ejido, San Pedro Soteapan, Veracruz).

${ }^{14} \mathrm{~A} G E V$, Secretaría de Gobernación, sección Gobernación y Justicia, serie Tierras, caja 442, exp. 31.

${ }^{15}$ Una detallada narración sobre la explotación petrolera en ambas regiones puede consultarse en Brown (1998).

${ }^{16}$ ACAM, expediente 1432, dotación de ejido, San Pedro Soteapan, Veracruz.

${ }^{17}$ En Soteapan -igual que en Mecayapan y Pajapanla presidencia municipal siempre ha sido ocupada por población originaria. En Soteapan, hasta la década de 1940 el presidente municipal tuvo entre sus funciones principales organizar el carnaval, una celebración dedicada a proteger el cultivo de maíz y evitar la entrada de enfermedades y calamidades al pueblo (Velázquez, 2006:283ss).

${ }^{18}$ Robles Berlanga (2000:126) señala que la dificultad para obtener la restitución de tierras radicó en que los pueblos que alegaban haber sido despojados de sus tierras, bosques y aguas, debían demostrar la propiedad de la tierra reclamada, así como la fecha y la forma del despojo. Numerosos pueblos no pudieron cumplir estos requerimientos, por lo que se procedió a dotarlos con tierras ejidales.

19 Por ejemplo, en Tatahuicapan, en ese entonces dependiente del municipio de Mecayapan, fue hasta 1963 que un perito agrario recibió la orden de ejecutar la diligencia de posesión provisional concedida desde 1952 (ACAM, exp. 2611). 
20 "Resolución sobre dotación de ejido al poblado Soteapan, municipio del mismo nombre, Estado de Veracruz", Diario Oficial de la Federación, 23 de diciembre de 1963, pp. 8-10.

${ }^{21}$ ACAM, expediente 1432, dotación de ejido para San Pedro Soteapan, Veracruz.

${ }^{22}$ Por ejemplo, en el ejido Cuilonia, del municipio de Soteapan, en 1974 ocurrió un enfrentamiento a balazos mientras se desarrollaba una asamblea ejidal, resultando muerto el presidente del comisariado ejidal y miembro de un grupo ganadero. Una confrontación similar ocurrió en el ejido Amamaloya, del mismo municipio, cuando en 1971 se desató un zafarrancho durante una asamblea ejidal (entrevistas a M.R., comisario ejidal de Cuilonia, 16 de julio de 2003, y a N.G., ejidatario de Amamaloya, 14 de julio de 2003.

${ }^{23}$ En la actualidad, permanecen sin parcelar los ejidos Sierra de Santa Martha (Soteapan) y Plan Agrario (Mecayapan), en donde sus integrantes rechazaron ingresar al PROCEDE, que en Veracruz culminó en el año 2006. Mantuvieron su negativa al parcelamiento de sus ejidos cuando en 2010 el visitador agrario de la Procuraduría Agraria les expuso la posibilidad de ingresar al Fondo de Apoyo para Núcleos Agrarios sin Regularizar (FANAR).

24 El Programa de Apoyos directos al Campo (PROCAMPO) fue aprobado por el Congreso de la Unión a finales de 1993, en vísperas de la firma del Tratado de Libre Comercio entre México, Estados Unidos y Canadá, y puesto en marcha en 1994. Este programa de apoyo al ingreso monetario de los productores, tenía como fin "compensar a los productores de granos básicos y oleaginosas por el impacto negativo que tendría la eliminación de los precios de garantía y los subsidios al comercio en el NAFTA [TLC]" (Davis, 2000:102).

${ }^{25}$ Datos obtenidos en www.phina.ran.gob.mx/phina2/ sessiones (consultado el 2 de noviembre de 2016).

26 Datos obtenidos en www.phina.ran.gob.mx/phina2/ sessiones (consultado el 2 de noviembre de 2016).

${ }^{27}$ En el municipio de Tatahuicapan, por ejemplo, hubo ejidos en los que el número de ejidatarios aumentó de 52 a 59 (San Francisco), o de 25 a 27 (Santanón Rodríguez) (disponible en: www.phina.ran.gob.mx/phina2/sessiones, consultado el 2 de noviembre de 2016).
${ }^{28}$ Entrevista a E.A., secretaria del Comisariado Ejidal, 6 de diciembre de 2017.

${ }^{29}$ Entrevista a S.F., exsecretario del Comisariado Ejidal, 20 de febrero de 2016.

${ }^{30}$ En el ejido Soteapan, cada ejidatario posee dos derechos parcelarios: uno en las áreas de labor, que puede amparar la posesión de hasta veinte hectáreas, y otro de alrededor de dos hectáreas en la zona de ocotales. Algunos de los ejidatarios foráneos han comprado estas últimas parcelas, que son improductivas y en las que a veces "han construido un ranchito al que sólo vienen en Semana Santa" (entrevista a S.F., exsecretario del Comisariado Ejidal, 20 de febrero de 2016).

${ }^{31}$ Cabe señalar que en la mayoría de los pueblos indígenas del sur de Veracruz sí se delimitaron y dividieron las tierras comunales (Velázquez, 2009).

32 Son cuatro los ejidos en los que la certificación parcelaria concluyó en la década del 2000: Popsojnas (2002), Ocozotepec (2004), San Fernando y Soteapan (2005) (disponible en: www.phina.ran.gob.mx/phina2/ sessiones, consultado el 3 de noviembre de 2016).

\section{Referencias}

Azaola Garrido, Elena (1982). Rebelión y derrota del magonismo agrario. México: SEP/FCE.

Azuela, Antonio (2010). "Property in the Post-postrevolution: Notes on the Crisis of the Constitutional Idea of Property in Contemporary Mexico". En Texas Law Review, 89:1915-1942.

Davis, Benjamín (2000). "Las políticas neoliberales de los ejidatarios frente a la reforma neoliberal en México". En Revista de la CEPAL, 72:99-119.

Flores López, José Manuel (2007). Transformaciones en la gestión de la tierra ejidal después del Procede. Ganadería y mercado de tierras en la Sierra de Santa Marta, Veracruz México. México: CIESAS.

García de León, Antonio (2004). Contra viento y marea. Los piratas en el Golfo de México. México: Plaza y Janés

Garner, Paul (2003). Porfirio Díaz. Del héroe al dictador: una biografía política. México: Editorial Planeta Mexicana.

Garner, Paul (2013). Leones británicos y águilas mexicanas. Negocios, política e imperio en la carrera de Weetman Pearson 
en México, 1889-1919. México: FCE/Instituto Mora/El Colegio de México/El Colegio de San Luis.

INEGI (Instituto Nacional de Estadística y Geografía) (2010). Censo de población y vivienda 2010. México: INEGI.

Lund, Christian (2011). "Property and Citizenship: Conceptually Connecting Land Rights and Belonging in Africa”. En Africa Spectrum, 46:71-75.

Prévôt-Schapira, Marie-France (1994). "El sur de Veracruz en el siglo XIX: una modernización a "marcha forzada". En Odile Hoffmann y Emilia Velázquez (coords.). Las llanuras costeras de Veracruz. La lenta construcción de regiones. Jalapa: Universidad Veracruzana/ORSTOM, pp. 245-278.

Procuraduría Agraria (1993). Nueva Legislación Agraria. Reglamento de la Ley Agraria en Materia de Certificación de Derechos Ejidales y Titulación de Solares. México: Procuraduría Agraria.
Robles Berlanga, Héctor (2000). "Propiedad de la tierra y población indígena”. En Estudios Agrarios, 14:123-147.

Sikor, Thomas y Christina Lund (2009). "Access and Property: A Question of Power and Authority”. En Development and Change, 40:1-22.

Velázquez Hernández, Emilia (2006). Territorios fragmentados. Estado y comunidad indígena en el Istmo Veracruzano. México: CIESAS/El Colegio de Michoacán.

Velázquez Hernández, Emilia (2009). "Las comunidades indígenas del Istmo veracruzano frente al proyecto liberal de finales del siglo XIX". En Emilia Velázquez y Odile Hoffmann (eds.), El Istmo mexicano: una región inasequible. Estado, poderes locales y dinámicas espaciales (siglos XVI-XXI). México: CIESAS/IRD, pp. 291-352.

Zorrilla Ornelas, Leopoldo (1998). "Presentación”. En Procuraduría Agraria. Los tratos agrarios en ejidos certificados. México: Procuraduría Agraria, pp. 7-9. 